\title{
Starting a Dialogue: Athletic Training Researchers and Clinicians
}

\author{
Jeffrey B. Driban, PhD, ATC, $\operatorname{CSCS}^{1}$ and R. Mark Laursen, MS, ATC ${ }^{2}$ \\ ${ }^{1}$ Tufts University School of Medicine; ${ }^{2}$ Boston University
}

"You can't stay in your corner of the Forest waiting for others to come to you. You have to go to them sometimes." A. A. Milne

Our patients deserve care that combines the best clinician experience and latest research evidence. However, there is a growing awareness of a gap between clinicians and researchers in sports medicine that hinders patient care by impeding translation to and from research and clinical practice. ${ }^{1,2}$ To address this gap, Esculier and colleagues ${ }^{1}$ created a call to action to ensure research findings are relevant to clinical practice, disseminated to clinicians, and spark the interest of clinicians. As well, research findings must be understandable, interpretable, and applicable to the clinical setting. These authors offered a few action items to achieve these goals:

1. Involve clinicians as treating clinicians, blind assessors, and stakeholders (e.g., providing input on study design and dissemination)

2. Encourage combined clinical and research roles

3. Create opportunities for clinicians and scientists to work in the same space

\section{What Can We Do in Athletic Training to Address the Gap?}

We can see the implications of this gap in athletic training where the gap exists between athletic training clinicians and researchers and is characterized by a failure of these groups to share wisdom and collaborate with one another. As long as athletic training researchers and clinicians operate in isolation, we will fall short of optimizing patient care. Clinicians, researchers, and other stakeholders, such as our patients, need to drive an effort to enhance patient care by bridging the gap between athletic training research and clinical practice. However, simply saying we need to bridge the gap is not enough. Instead, we need new ways to fill the gap and ensure that the gap between research and clinical practice never reappears. This challenge demands new channels of communication between clinicians, researchers, and other stakeholders. Hereafter, we propose activities to create a strong collaborative relationship between

Driban is a research associate professor in the Division of Rheumatology, Allergy \& Immunology at Tufts University School of Medicine, Boston, MA, and is a member of the Special and Scientific Staff at Tufts Medical Center. He is an associate editor for the IJATT, the co-founder of Sports Medicine Research (SMR), and a founding member of the Athletic Training Osteoarthritis Consortium (ATOAC). Laursen is a clinical associate professor and director of Athletic Training Services within the Department of Physical Therapy and Athletic Training at Boston University, Boston, MA. He is a founding member of the Athletic Training Research Network (ATCEN) and is a past president of the Commission on Accreditation of Athletic Training Education (CAATE). Driban (jeffrey.driban@tufts.edu) is corresponding author. athletic training research and clinical practice. We also provided a table that summarizes the suggestions for things clinicians and researchers can do to help readers develop new lines of communication between research and clinical practice (see Table 1).

\section{What Can Athletic Training Clinicians Do?}

Athletic training clinicians should share their experience and wisdom with other clinicians, educators, and researchers. For example, an athletic training clinician could develop a clinical CASE report about a successful treatment or education strategy as well as an area of concern. ${ }^{3,4}$ Specifically, an exploration case study is a great opportunity for a clinician to describe a novel or atypical presentation in their clinical practice. The goal is to provide practice-based evidence that may offer new insights into diagnostic, prognostic, therapeutic, or etiologic factors related to a particular condition..$^{5}$ Alternatively, a clinician could also consider a validation case study. A validation case study provides a powerful opportunity to describe how a treatment strategy, which was efficacious in a clinical trial, performed in the real world. These case studies offer the clinician a chance to provide insight into factors (e.g., What are patients willing to do, do properly, or continue to do?) that may influence the effectiveness of a treatment strategy. ${ }^{6}$ These clinical CASE reports also provide clinicians and researchers an invaluable insight that can improve patient care and inspire new research studies and collaborations.

\section{What Can Athletic Training Researchers Do?}

Athletic training researchers should make their findings more readily available and digestible to athletic training clinicians. A researcher should strive to prepare papers and presentations that offer clinical take-home messages in plain language. These take-home messages should explain how a clinician could implement the new findings into clinical practice. An athletic training researcher should also disseminate new knowledge directly to clinicians via social media, online webinars, online chats, magazines, newsletters, presentations for education programs, and other communication strategies that will help raise awareness about their latest findings. ${ }^{7}$ The publication of a manuscript or presentation at a meeting should not be the end of the story for that study, but the beginning of a new chapter that is focused on marketing the new findings to the appropriate audience.

\section{Starting a Dialogue: What Can Athletic Training Researchers and Clinicians Do Together?}

We encourage athletic training clinicians and researchers to sit down together and have discussions about what is seen in the clinic, 


\section{Table 1 Activities to Bridge the Gap Between Athletic Training Research and Clinical Practice}

\begin{tabular}{ll}
\hline Clinician & Researcher \\
\hline $\begin{array}{l}\text { Share your experience and wisdom (e.g., publish } \\
\text { CASE studies) }\end{array}$ & $\begin{array}{l}\text { Write manuscripts that are accessible to clinicians and include take-home messages } \\
\text { about the clinical implications of the findings }\end{array}$ \\
$\begin{array}{l}\text { Attend free-communication sessions and ask questions or } \\
\text { offer perspective }\end{array}$ & $\begin{array}{l}\text { Share peer-reviewed results beyond the published manuscript (e.g., magazines, social } \\
\text { media, state/district meetings, national meetings) } \\
\text { Invite local researchers to your clinic }\end{array}$ \\
$\begin{array}{l}\text { Meet with local athletic trainers to discuss your research, how it fits into their clinical } \\
\text { practice, and perceived barriers to implementation }\end{array}$ \\
$\begin{array}{l}\text { Participate in stakeholder committees and research studies } \\
\begin{array}{l}\text { Present with researchers } \\
\text { Call or email an author of a paper to ask a question or share an } \\
\text { anecdote }\end{array}\end{array}$ & $\begin{array}{l}\text { Present with clinicians } \\
\text { Be accessible-participate in live online chats or webinars }\end{array}$ \\
\hline
\end{tabular}

what is the latest evidence, how to implement the latest evidence, and how an implementation strategy worked. In Boston, athletic trainers at Boston University and Tufts Medical Center started to develop this relationship. The process started when the two of us (Driban and Laursen) were sitting in a focus group together (over 1,500 miles from home) and recognized our common interest in promoting strategies to protect the long-term wellness of physically active individuals. While we had known each other for several years, it was not until this coincidental discussion that we realized our common interest. This story highlights the need for athletic training researchers and clinicians to initiate dialogues within our own communities and discover common interests. After a few discussions about how to build on our initial discussion, Boston University hosted a meeting where athletic training researchers from Tufts Medical Center presented to the clinical staff the latest evidence related to the risk of osteoarthritis among certain athletes (e.g., those with a history of injury). After a brief presentation, we discussed what is being seen in the clinic and how it is addressed, what the latest evidence tells us about certain types of patients, and how we can talk to a college student about their long-term wellness. After this meeting, a dialogue was continued through similar presentations to the athletic training education programs as well as through clinical athletic trainers being able to call a researcher for advice about what evidence they can offer a patient about their potential risk for longterm outcomes. This relationship can help improve patient care and inspire new research to improve patient care.

Conversations between athletic training clinicians and researchers also helps to inform and refine the research process from start to finish. Athletic training researchers should consider developing stakeholder committees for projects that include athletic training clinicians and relevant patients (e.g., patients with chronic ankle instability or knee injuries). These stakeholders can offer input into study design by advising researchers on what may be feasible or desirable in a clinical setting. The stakeholder committee can also be a valuable resource that helps alerts researchers of changes in clinical practice during a study and interprets results. Ultimately, the stakeholder committee can be a key resource to ensuring that the results of the study are relevant and interesting to clinicians.

Upon completion of a clinical research study, it is very helpful to involve clinicians in meetings and presentations to discuss the latest evidence and how it can be incorporated into practice. In this effort, at their annual meeting, the National Athletic Trainers' Association is hosting a session titled, "Life After Athletics: Long Term Considerations for Lower Extremity Injuries". This 1-hr feature presentation will include a presentation by two researchers: Dr. Lindsay DiStefano will discuss the latest evidence for injury prevention and Dr. Brian Pietrosimone will present the latest evidence for what we can do after an injury to reduce the risk of poor long-term outcomes. The session will also include Mark Laursen, the Director of Athletic Training Services at Boston University, who will discuss his experience on how and why we need to educate athletes about wellness after athletics. The question and answer session at the end of this session will offer attendees an invaluable opportunity to have their questions answered by a group with a rich experience in research and clinical practice.

Besides having researchers and clinicians present together, it is also important to ensure that state, district, and national freecommunication sessions-where the most cutting-edge research is often presented-are inviting to athletic training researchers and clinicians. This requires an athletic training researcher to ensure their presentation (oral or poster) helps a clinician understand why the study was done and how the methods could be applied in a clinical setting. Furthermore, instead of ending a presentation with future research directions or re-iterating the results, it would be helpful if athletic training researchers provided a plain language clinical take-home message to explain how a clinician could implement the key findings in clinical practice. It is also invaluable to have clinicians attend these free-communication sessions to ask presenters to describe salient points that may influence how these new findings could influence clinical practice. With clinicians asking questions in the audience, it can help other clinicians better understand the clinical implications of these new results, and, for younger presenters, it can push them to become better communicators to clinicians. Free-communication sessions can offer small, intimate settings for clinicians and researchers to engage one another and these sessions should become part of our front line to overcoming the gap between athletic training clinicians and researchers.

Building these new lines of communication in athletic training will take time, but, for our patients, we should continue to work on them. Our hope is to inspire clinicians and researchers to bridge the gap and to work together to promote better clinical care and clinical research. Working together, we can inspire new treatment and education strategies.

\section{References}

1. Esculier JF, Barton C, Whiteley R, Napier C. Involving clinicians in sports medicine and physiotherapy research: 'design thinking' to help bridge gaps between practice and evidence. $\mathrm{Br} J$ Sports Med. 2018;52(24):1550-1551. PubMed ID: 30368443 doi:10.1136/ bjsports-2018-100078 
2. Verhagen E, Voogt N, Bruinsma A, Finch CF. A knowledge transfer scheme to bridge the gap between science and practice: an integration of existing research frameworks into a tool for practice. Br J Sports Med. 2014;48(8):698-701. PubMed ID: 23757487 doi:10.1136/ bjsports-2013-092241

3. McKeon PO, Medina McKeon JM, King MA. Case studies: the alpha and omega of evidence-based practice. Int J Athl Ther Train. 2014; 19(6):1-3. doi:10.1123/ijatt.2014-0117

4. Medina McKeon JM, King MA, McKeon PO. Clinical contributions to the available sources of evidence (CASE) reports: executive summary. Int J Athl Ther Train. 2016;21(6):1-7. doi:10.1123/ijatt.2016-0097
5. McKeon PO, Medina McKeon JM. Evidence-based practice or practice-based evidence: what's in a name? Int J Athl Ther Train. 2015;20(4):1-4. doi:10.1123/ijatt.2015-0055

6. Medina McKeon JM, McKeon PO. Patient evidence (AKA, boy, patients complicate our clinical practice). Int J Athl Ther Train. 2017;22(6):1-4. doi:10.1123/ijatt.2017-0088

7. Driban JB. Tapping into the evidence pipeline - the role of social media in evidence-based practice. Int J Athl Ther Train. 2016;21(3): 1-4. doi:10.1123/ijatt.2016-0032 